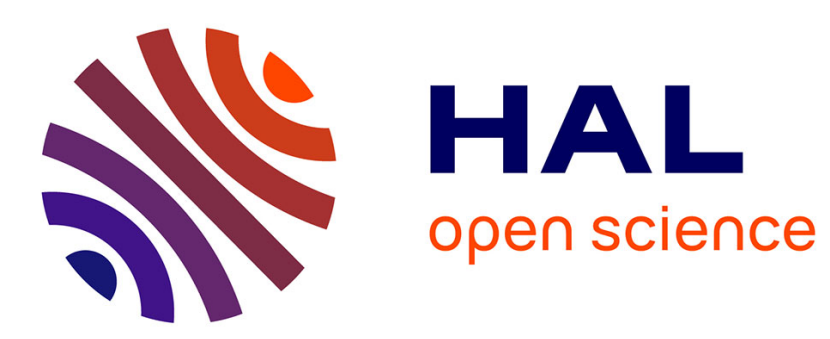

\title{
Conservative management of primary spontaneous pneumothorax: A failed revolution?
}

\author{
S Jouneau, L Sohier, Y Bazin, A Salé, J Messika
}

\section{To cite this version:}

S Jouneau, L Sohier, Y Bazin, A Salé, J Messika. Conservative management of primary spontaneous pneumothorax: A failed revolution?. Respiratory Medicine and Research, 2021, 79, pp.100796. 10.1016/j.resmer.2020.100796 . hal-03094940

\section{HAL Id: hal-03094940 \\ https://hal.science/hal-03094940}

Submitted on 12 Jan 2021

HAL is a multi-disciplinary open access archive for the deposit and dissemination of scientific research documents, whether they are published or not. The documents may come from teaching and research institutions in France or abroad, or from public or private research centers.
L'archive ouverte pluridisciplinaire HAL, est destinée au dépôt et à la diffusion de documents scientifiques de niveau recherche, publiés ou non, émanant des établissements d'enseignement et de recherche français ou étrangers, des laboratoires publics ou privés. 


\section{Editorial}

Conservative management of Primary Spontaneous Pneumothorax: a failed revolution?

Stéphane Jouneau ${ }^{1,2}$, Laurent Sohier ${ }^{3}$, Yann Bazin ${ }^{4}$, Alexandre Salé ${ }^{1}$, Jonathan Messika ${ }^{5}$.

${ }^{1}$ Department of Respiratory Medicine, Competence Centre for Rare Pulmonary Diseases, CHU Rennes, Rennes, France

${ }^{2}$ Univ Rennes, CHU Rennes, Inserm, EHESP, IRSET (Institut de recherche en santé, environnement et travail) - UMR_S 1085, F-35000 Rennes, France.

${ }^{3}$ Department of Respiratory Medicine, Centre Hospitalier Bretagne Sud, Lorient, France

${ }^{4}$ Department of Respiratory Medicine, Centre Hospitalier de St Malo, St Malo, France

${ }^{5}$ Hôpital Bichat Claude Bernard, APHP.Nord - Université de Paris, INSERM UMR 1152, Paris, France

\section{Correspondence:}

Prof. Stéphane Jouneau

Service de pneumologie, Centre de Compétences pour les Maladies Rares Pulmonaires,

Hôpital Pontchaillou, UMR 1085, IRSET, Université de Rennes 1, 2 rue Henri Le Guilloux, 35033 Rennes Cedex 9, France

Tel: +33 (0)2.99.28.24.78 / Fax: +33 (0)2.99.28.24.80

$\underline{\text { Stephane.jouneau@chu-rennes.fr }}$

Conflict of interest: none.

Funding: none

Keywords: chest tube, aspiration, ambulatory, non-invasive, large, out-patient. 
A spontaneous pneumothorax can be primary (PSP) or secondary (SSP) (1). PSP is defined as a spontaneous pneumothorax occurring in a patient who has no known underlying lung disease; it is a frequent, benign condition in tall young male smokers (2). PSP management is designed to cure the current episode and prevent/reduce recurrence, which can reach $29 \%$ in the first year (3).

The guidelines for PSP management are conflicting, with several different strategies $(1,2,4)$. All the guidelines for small PSP without significant breathlessness agree: patients should be observed and discharged if stable $(1,2,4)$.

The lack of consistency among guidelines for treating large PSPs is probably due to wide variations among centres $(5,6)$. Some physicians advocate surgery as first-line treatment despite the fact that most patients (70\%) will never have a recurrence (3). This includes $15 \%$ of the American College of Chest Physicians (ACCP) guideline panel (4). The management of most large PSPs around the world is invasive, with chest-tube drainage (CTD) or manual aspiration (MA) $(1,2,4)$.

A randomised controlled trial on Australian and New Zealand PSP patients published recently in the New England Journal of Medicine raises questions about these practices (7). Brown et al. demonstrated that a conservative strategy was in non-inferior to a standard CTD for treating a first episode of large PSP (7). The conservative management consisted of a 4-hour observation period, followed by discharge home with ambulatory follow-up. These interesting findings are consistent with those reported by Stradling and Poole (8) more than half a century ago. Surprisingly, these results did not trigger a revolution in PSP management; conservative management has not gained support - it has actually lost some influence in various guidelines (9).

However, it is wise to examine the details of the study before using conservative management for all patients with a first episode of PSP, whatever its size.

First, some statistical facts are troubling. As stressed by the authors, 60/316 of the conservativemanagement patients had no chest X-ray at week 8. A sensitivity analysis was therefore performed: all data missing at 56 days were considered to be treatment failures. As a result, the risk difference was outside the specified non-inferiority margin, making the trial negative. Furthermore, only 316 of the 2637 patients screened (12\%) were included, suggesting inclusion bias. 
Second, the symptoms persisted for longer than usual, around 40 hours, and patients were almost asymptomatic (mean Borg dyspnea around 1.5). This is consistent with the inclusion bias: the patients for this trial were selected from among the general PSP population.

Third, the primary endpoint, success at 8 weeks, is remarkably late and long after the PSP event. Most trials on large PSP use an immediate success rate; any delayed success is still assessed only a few days to a week post-PSP (10-18).

Moreover, we not at all sure that French PSP patients treated conservatively, without complete lung re-expansion, would be back at work as fast in these Australian and New Zealand men. The median time to radiographic resolution was 30 days (interquartile range, 25 - 54 days) for the conservatively-managed group and their median number of days off work was 6.0 (2 - 14). This trial design would not be applicable in real life in France.

There is yet another suggestion of an inclusion bias in the study of Brown et al.. The published recurrence rate in the conservative arm $(8.8 \%)$ was significantly lower than that of the interventional arm (16.8\%) (8). These rates seem very low, especially when compared to the $29 \%$ pooled one-year rate reported in a recent meta-analysis (3).

Our final, and perhaps most important point, concerns patient discharge. If the protocol is strictly followed, a PSP patient admitted to Emergency with a respiratory rate of 28/min, pulsed oxygen saturation of $91 \%$ in room air, and a mediastinal shift on chest X-ray, could be discharged and treated conservatively if he is stable after 4 hours! We would not feel very comfortable with such management.

We believe the main finding of this trial is that PSP is a benign condition, with a spontaneously favorable evolution. Any invasive strategy should therefore be subjected to a strict risk-benefit analysis.

A conservative management strategy could therefore be used for a very stable patient with slight dyspnea, provided the distance between the chest wall and lung margin is 3 or $4 \mathrm{~cm}$ at the hilum, or maybe slightly more. This should lead to revision of the definition of "small" PSP in the next few years.

The simple, easy-to-use material presently available should allow a minimally invasive strategy to be used for patients with a large PSP. Patients who can undergo rigorous surveillance could be eligible for ambulatory management after successful MA $(10,18)$ or with the small-size CTD connected to a one-way valve $(14,19-21)$, provided that the patient's safety is assured. 
French guidelines coordinated by the French-Speaking Respiratory Society (SPLF) in collaboration with the Emergency Medicine (SFMU), French Intensive Care (SRLF), Thoracic Surgery (SFCTCV), and Anesthesiology (SFAR) Societies are in preparation, and should be available in 2021.

Further studies are still needed to define the optimal management of first-episode PSP patients. Each of the four therapeutic options has its target population. Invasive management should be now prohibited for such a benign, frequent disease, as Brown et al. point out. Conservative management should be restricted to patients with perfect tolerance, whose PSP evolves favourably and rapidly, and for the moment, these patients are the one suffering from "small" PSP. A minimally invasive ambulatory strategy (i.e. MA or small-size CTD with one way valve) should be proposed for patients requiring prolonged lung re-expansion. And finally, surgery should be proposed to patients with high-risk recurrence PSP. We still need to improve our knowledge of the phenotypes / genotypes / endotypes of these patients so that we can choose wisely the best management for each individual patient. This is still science fiction but "May the Force be with us"!

\section{References}

1. Tschopp JM, Bintcliffe O, Astoul P, Canalis E, Driesen P, Janssen J, et al. ERS task force statement: diagnosis and treatment of primary spontaneous pneumothorax. Eur Respir J. 2015;46(2):321-35.

2. MacDuff A, Arnold A, Harvey J, Group BTSPDG. Management of spontaneous pneumothorax: British Thoracic Society Pleural Disease Guideline 2010. Thorax. 2010;65 Suppl 2:ii18-31.

3. Walker SP, Bibby AC, Halford P, Stadon L, White P, Maskell NA. Recurrence rates in primary spontaneous pneumothorax: a systematic review and meta-analysis. Eur Respir J. 2018;52(3).

4. Baumann MH, Strange C, Heffner JE, Light R, Kirby TJ, Klein J, et al. Management of spontaneous pneumothorax: an American College of Chest Physicians Delphi consensus statement. Chest. 2001;119(2):590-602.

5. Contou D, Schlemmer F, Maitre B, Razazi K, Carteaux G, Mekontso Dessap A, et al. Management of primary spontaneous pneumothorax by intensivists: an international survey. Intensive Care Med. 2016;42(9):1508-10.

6. Kepka S, Dalphin JC, Pretalli JB, Parmentier AL, Lauque D, Trebes G, et al. How spontaneous pneumothorax is managed in emergency departments: a French multicentre descriptive study. BMC Emerg Med. 2019;19(1):4.

7. Brown SGA, Ball EL, Perrin K, Asha SE, Braithwaite I, Egerton-Warburton D, et al. Conservative versus Interventional Treatment for Spontaneous Pneumothorax. N Engl J Med. 2020;382(5):405-15.

8. Stradling P, Poole G. Conservative management of spontaneous pneumothorax. Thorax. 1966;21(2):145-9. 
9. Miller AC, Harvey JE. Guidelines for the management of spontaneous pneumothorax. Standards of Care Committee, British Thoracic Society. BMJ. 1993;307(6896):114-6.

10. Thelle A, Gjerdevik M, SueChu M, Hagen OM, Bakke P. Randomised comparison of needle aspiration and chest tube drainage in spontaneous pneumothorax. Eur Respir J. 2017;49(4).

11. Parlak M, Uil SM, van den Berg JW. A prospective, randomised trial of pneumothorax therapy: manual aspiration versus conventional chest tube drainage. Respir Med.

2012;106(11):1600-5.

12. Ho KK, Ong ME, Koh MS, Wong E, Raghuram J. A randomized controlled trial comparing minichest tube and needle aspiration in outpatient management of primary spontaneous pneumothorax. Am J Emerg Med. 2011;29(9):1152-7.

13. Ayed AK, Chandrasekaran C, Sukumar M. Aspiration versus tube drainage in primary spontaneous pneumothorax: a randomised study. Eur Respir J. 2006;27(3):477-82.

14. Massongo M, Leroy S, Scherpereel A, Vaniet F, Dhalluin X, Chahine B, et al.

Outpatient management of primary spontaneous pneumothorax: a prospective study. Eur Respir J. 2014;43(2):582-90.

15. Noppen M, Alexander P, Driesen P, Slabbynck H, Verstraeten A. Manual aspiration versus chest tube drainage in first episodes of primary spontaneous pneumothorax: a multicenter, prospective, randomized pilot study. Am J Respir Crit Care Med.

2002;165(9):1240-4.

16. Andrivet P, Djedaini K, Teboul JL, Brochard L, Dreyfuss D. Spontaneous pneumothorax. Comparison of thoracic drainage vs immediate or delayed needle aspiration. Chest. 1995;108(2):335-9.

17. Marquette CH, Marx A, Leroy S, Vaniet F, Ramon P, Caussade S, et al. Simplified stepwise management of primary spontaneous pneumothorax: a pilot study. Eur Respir J. 2006;27(3):470-6.

18. Vuillard C, Dib F, Achamlal J, Gaudry S, Roux D, Chemouny M, et al. Longer symptom onset to aspiration time predicts success of needle aspiration in primary spontaneous pneumothorax. Thorax. 2019;74(8):780-6.

19. Hallifax. RJ, McKeown. E, Sivakumar. P, Fairbairn. I, eter. C, Leitch. A, et al. Ambulatory management of primary spontaneous pneumothorax: an open-label, randomised controlled trial. Lancet 2020;396: :39-49.

20. Sale A, Sohier L, Campion M, Le Ho R, Bazin Y, Gangloff C, et al. Exclusive ambulatory management of spontaneous pneumothorax with pigtail catheters, a prospective multicentric study. Respir Med. 2020;166:105931.

21. Voisin F, Sohier L, Rochas Y, Kerjouan M, Ricordel C, Belleguic C, et al. Ambulatory management of large spontaneous pneumothorax with pigtail catheters. Ann Emerg Med. 2014;64(3):222-8. 